\title{
How Do You Read a Sign that No One Has Ever Seen Before? A Post-Semiotic Analysis of Chance-Driven Events
}

\section{Dean Wilcox}

We are used to, in the past, this idea that artists make defined finished things which the public then looks at. This is slightly different. This is like creating a seed and planting it . . . and it grows into whatever it grows into.

I was first introduced to semiotics while working toward an MFA in lighting design. My initial reaction was to dismiss it as needlessly complicated. I thought, "Yeah, I got it. Things mean things. Why do I need to learn a new language to talk about that?" But slowly the ideas, vocabulary, and insights afforded by semiotics began to unlock previously unseen ways of analyzing and discussing performances. Dissecting how a production signified, or at the very least, was put together, allowed me to understand better how I might approach the design process myself. Things still meant things, but now manipulating those elements and the context within which they were viewed became a much more complex and fertile procedure.

As designer gave way to critic and scholar, I was drawn to performances that acknowledged the complexity of the semiotic process by toying with signification. The rich and varied work of people like Robert Wilson, Meredith Monk, and Richard Foreman simply dripped with signs begging to be explored. Semiotics was a good first step in discussing this material but never quite seemed to capture everything that transpired in performance. The convergence of performance elements seemed to exceed the language of semiotics, indicating a need to move beyond semiotics for a more comprehensive method of analysis. I began to investigate other methodologies-deconstruction, phenomenology, chaos theory-which in one way or another draw on semiotics, but also offer specialized languages and ideas that aid in exploring elements surpassing the semiotic frame.

My journey, as it turns out, is not all that unique. In the "post"-script to the

Dean Wilcox is Assistant Dean for the Undergraduate Academic Program at the North Carolina School of the Arts where he teaches The Aesthetics of Dissonance, Chaos Theory and the Arts, Postmodern Drama, and Performance Art. In addition to working periodically as a lighting designer, he has published articles and book reviews in Theatre Journal, Theatre Survey, the Journal of Dramatic Theory and Criticism, Theatre Research International, and Modern Drama on topics such as the intersection of semiotics and phenomenology, Josef Svoboda's multimedia design for Intolleranza, the convergence of chaos theory and performance, Karen Finley's deconstructive technique, and ambient space in twentieth-century theatre. 
second edition of his influential Semiotics of Theatre and Drama, Keir Elam discusses the pragmatic and methodologically conservative approach of British and American theatre:

Semiotic performance analysis, being itself an 'avant-garde' and methodologically anti-traditionalist endeavor, tended to look for its objects and for its ideal models of theatricality precisely in the avant-garde, anti-traditionalist forms of theatre, in the hope of bringing about a "natural" alliance or symbiosis between theory and practice. ${ }^{1}$

What is it about the avant-garde that is both attractive to critics using semiotics and brings about the development of postsemiotics? While the entirety of this question is beyond the scope of this paper, I propose to focus on a few key avant-garde elements - chance and indeterminacy.

The term "post" is a very popular modifier when added to structuralism, modernism, semiotics, and "dramatic," suggesting something beyond, an evolutionary trope that indicates time and movement, but also incorporates the very idea it exceeds. As Hans-Thies Lehmann articulates in Postdramatic Theatre, a genre that develops in conjunction with the postsemiotic, "the prefix 'post' indicates that a culture or artistic practice has stepped out of the previously unquestioned horizon of modernity but still exists with some kind of reference to it." ${ }^{2}$ The concept of "post" indicates a palimpsest in which past and present co-exist. As long as someone somewhere is performing an un-ironic version of The Crucible, the postdramatic will share the stage with the dramatic. As long as critics are willing to analyze performances using "signifier" and "signified" without complicating this method, postsemiotics will reside alongside semiotics.

One thing I admire about Roland Barthes's writing is his acknowledgement of the limitations of his analysis. Clear in articulating his project, he was also clear when he had reached an impasse. In "The Third Meaning" he states, "The obtuse meaning is a signifier without a signified, hence the difficulty in naming it. My reading remains suspended between the image and its description, between definition and approximation." A few lines later he is even more specific: "how do you describe something that does not represent anything?"3 Or, as he asks in "The Rhetoric of the Image," "How does meaning get into an image? Where does it end? And if it ends, what is there beyond?"4 Barthes took his rigorous semiotic analysis as far as it would go and then pointed to something that eluded his grasp. He could sense it, discuss it, and even narrate the process by which he could access it, but ultimately, by using semiotics, Barthes reached an analytical impasse.

This idea of the limitations of analysis is something that Michael Kirby takes up in a formalist theater when he builds on Umberto Eco's idea of semiotic acts 
in relation to interpretation within a specific cultural or systematic code. For Kirby, "semiotics, then, is not the exegesis of meaning but the demonstration of how meaning derives from a particular code; unless the code itself is clear, we have only interpretation." Semiotics, in this case, can never bring the critic to an understanding of the meaning of a work, only $a$ meaning, suggesting that there are alternative methods to employ.

Kirby also raises the spatial, temporal, and ideological question of where signs and sign systems end in relation to performance. ${ }^{6}$ When and where do we begin our analysis? This is a seemingly simple question when dealing with traditional performances that offer a defined starting point by darkening the auditorium and raising the curtain, but much more complicated when dealing with the avant-garde. Are we limited to analyzing elements that support the narrative, or can we discuss things that are external to this, such as the program, the lobby experience, or repeated viewings? Do we draw a line at the edge of the stage and ignore physical elements outside this space, or do we follow Marvin Carlson's lead in Places of Performance and explore architecture, neighborhood, and city? What do we concentrate on if no narrative is employed, or if the performance works to disrupt the text? If spectators are expected to contemplate the performance and put it together for themselves, when do we consider this process complete? As Elam suggests, the lines are drawn much clearer in traditional performances, but these questions are crucial when dealing with avant-garde forms that deliberately disrupt signification.

In retrospect, the use of semiotics as a way of bolstering performance analysis was fated to give rise to contention. Even early semiotic analysis acknowledged the complexity of the theatre as a composite art made up of many sign systems and codes. It was obvious that one single methodology, no matter how powerful, would never be able to capture the whole. Commenting on this limitation in Great Reckonings in Little Rooms, Bert States suggests that "any critical perspective is doomed to be narrow. It must be itself with a vengeance if it is to realize its potential for illumination." States continues, discussing this narrowness with regards to semiotics. "What is disturbing, if anything, about semiotics is not its narrowness but its almost imperialistic confidence in its product; that is, its implicit belief that you have exhausted a thing's interest when you have explained how it works as a sign." States ultimately argues against reading performances as an accumulation of signs in favor of phenomenological analysis. ${ }^{8}$

Unlike semiotics, which posits the signifying and therefore referential aspect of stage elements, phenomenology works to capture the immediate essence of performance. ${ }^{9}$ By setting judgments aside, including the process of reading and categorizing signs and sign systems, the spectator is able to focus on the present experience. Like most analytical methods, semiotics is always mediated, that is, always removed from the ebb and flow of the event, reflecting back on how signs and sign systems operated. Phenomenology, on the other hand, concentrates on 
the "first four seconds" of awareness, the moment "in which an object or an image establishes itself in our perception as something." ${ }^{10}$ For States, "semiotics and phenomenology are best seen as complementary perspectives on the world and on art." One method is concerned with mimetic and reproduced elements, while the other concentrates on elements perceived in the present moment.

Semiotics suggests that pure presence on stage is impossible since meaning is always deferred, always dispersed, never of the moment, never purely present, always a reflection of something that is past or absent. While this may be the case theoretically, it appears differently in performance. The process of taking the stage, no matter how rehearsed, re-produced, re-presented, or indicative of past or absent actions, is a moment filled with doubt. While a performance may rest on the convergence of signs and sign systems, to read it simply as a conglomeration of signifying pieces is to miss the point and the power of the "present" moment. "What will happen this time?" is the key question for live performance. Despite preparation, it is the element of uncertainty that drives the reception of performance elements beyond the sign toward the phenomenon.

Live performance always involves an element of chance, whether in construction or execution. Missteps, mistakes, and errors, however, are often subsumed into the overall structure of the piece in rehearsal, ignored, or viewed as an interruption to performance. There is a clear line drawn in which these accidental elements are viewed as external to the execution of the event, suggesting a division between rehearsed signification and unintentional signification. In discussing the avant-garde, Kirby employed the idea of an "analytical continua" in which the poles of "life" and "art," "acting" and "non-acting," "referential" and "non-referential" are boundary points between which elements can be explored as either closer to or further from a specific idea. ${ }^{12}$ Following States, we can add the continuum located between semiotics and phenomenology, and it is here where the contained signification of the rehearsed performance meets the capriciousness of the live event. Although this convergence of the intentional and the unintentional is central to any performance, I propose moving beyond mere happenstance to focus on the deliberate use of chance and indeterminacy.

Historically, the avant-garde, from Symbolism onward, concentrated on an expansion of meaning by transcending the confines of the material world. Establishing the goal of ambiguity, or what Edgar Allen Poe might call a "suggestive indefiniteness," ${ }^{13}$ the Symbolists replaced meaning with meaning $s$ and courted an intentional play of signification that never quite settled into a recognizable code. The Dadaists, following the Futurists, built on this foundation to create a sense of chance and play that far surpassed their predecessors. As Tristan Tzara points out, "I write this manifesto to show that people can perform contrary actions together while taking one fresh gulp of air; I am against action; for continuous contradiction, for affirmation too, I am neither for nor against and I do not explain because I hate 
common sense." 14

From manifesto to text to performance, deliberate contradictions became a hallmark of the avant-garde. Attacking the aesthetic values of Western art, the Dadaists employed chance as a central element to disrupt the notion of a wellordered and closed system. Tzara's advice, for example, on making a Dadaist poem includes choosing a newspaper article as long as you want the poem to be, cutting it up into individual words, tossing them in a bag and pulling them out one at a time. ${ }^{15}$ Here the continuum between semiotics and phenomenology is somewhat balanced. In order to appreciate Tzara's Dadaist poem in performance (that is, as the words are being drawn from the bag) the spectator must understand the words expressed in a significant way while also being aware of their immediate and randomly generated context. Yes, the poem has meaning as well as structure, but both are suspended between the execution and the reception as the artist and audience are privy to the results simultaneously.

To discuss signification is, in one respect, to discus meaning, or at least intention, and while it is possible to demonstrate a breakdown in communication, a message is nevertheless sent. This process, difficult when dealing with deliberate artistic choices and a contained and linear structure, becomes even more complex when chance is employed. Since avant-garde performance often deliberately sends ambiguous messages, what then is the role of semiotics? If meaning is dispersed, what is left for semiotic analysis to identify outside of potential meanings, possible intentions, or form and structure by way of ignoring content? As Elam states, the attraction for critics employing this method to such semiotically taxing material is the hope of aligning theory and practice. Ironically, the move from exploring the semiotically restrained to the semiotically rich led directly to a questioning of this methodology.

The use of chance as an artistic device reached an apex with John Cage's influential ideas on indeterminacy and non-intention. In his wake the areas of music, film, theatre, dance, and the visual arts were affected by this watershed concept. By offering a collision of structure and spontaneity, indeterminate and chance-driven performances blur the line between art and life, semiotics and phenomenology. For Cage, the use of chance elements such as coin tosses, consultation of the $I$ Ching, and even responding to irregularities in the paper used for notation was a systematic process for creating performance scores. "Most people who believe that I'm interested in chance don't realize that I use chance as a discipline. They think that I use it as a way of giving up making choices. But my choices consist in choosing what questions to ask." ${ }^{16}$ Chance, then, is viewed as a compositional tool to create controlled and deliberate works capable of integrating unplanned elements.

Certainly Cage's contributions to the development of Happenings, Fluxus activity, postmodern dance, and contemporary music are well documented. My intent here is to discuss these contributions as helping to propel the shift from semiotic 
analysis to postsemiotics. Although similar to chance, the idea of indeterminacy is perhaps a clearer mixture of the planned and unplanned. As Kirby points out, "Indeterminacy means that the limits within which the performers are free to make choices are provided by the creator of the piece: a range of alternatives is made available from which the performer may select." This differs from improvisation since the parameters of the piece have been set, but the execution, as Kirby states "is not "open ended' as it is in improvisation." 17

Take Cage's 1951 piece Imaginary Landscape Number 4, which is scored to be precisely executed by using twelve radios with specific instructions as to volume, tuning, and duration. Cage created a controlled and determined performance structure that included an indeterminate element, the radio, capable of producing music, talk, static, silence, and sounds at the very edge of audibility. Semiotics collides with phenomenology here as the material transmitted by each individual radio signifies in a precise and meaningful way, but is apprehended within a context that actively works to disrupt this signification. The goal, as Richard Schechner points out, is "the use of a machine which will short circuit human intention."18

Cage, along with Merce Cunningham, Robert Rauschenberg, David Tudor, and others, created another well-known piece at Black Mountain College in 1952 that further developed these ideas. Organized as a series of "compartmentalized" actions, independent actions performed in sequence or simultaneously, the intention of the piece was, as Cage states, "non-intention." 19 The structure revolved around a sequence of time brackets which performers were free to fill as they saw fit with such elements as sound, movement, images, and text. Unlike Cage's use of the radios, a device that does not make decisions, performers have agency, and no matter how unintentional their actions may be, they still exercise choice. Layering and juxtaposing compartmentalized actions derived from individual agency, however, produces an unpredictable variety. The end result, as transpired with Imaginary Landscape Number 4, was that the process of signification was disrupted and the spectator was left to construct an individual meaning from fragmented actions. This compartmentalization influenced the succeeding generation of "postdramatic" artists, including Wilson, Foreman, and Monk, who offer more structured pieces, but with a similarly fragmented organization.

Once again, the convergence of semiotics and phenomenology is key to this form of performance. Although solitary actions and images may be understood to signify in a clear and definite way, when presented simultaneously or in sequence with other, more diverse actions, the spectator is left to negotiate the rift between meaning and meanings, between signification and phenomenon. Semiotics suggests that all elements on stage are signs - that is, they point to something other than themselves - and it is this assumption that implies that performances already contain meaning prior to being viewed by a spectator. This is not true of indeterminate and chance-driven events since both artist and audience view the outcome as it 
unfolds in real time.

"Fixed" performances do not rely on the creation of meaning in performance, but the display of contained and rehearsed signs and referents. Employing chance and indeterminacy disrupts referentiality as signs are continually recontextualized within the present moment. It is this intersection between sign and phenomenon that is formed by utilizing familiar elements, like a newspaper article or a radio, in unfamiliar ways. Through the creation of unique, randomly generated images and actions, these performances present dynamic phenomenological events that are dependent on the process of signification. As a product of the "post" world, this type of activity rests at, not the juncture of the either/or of semiotics/phenomenology, but the both/and of poststructuralism in which neither method is privileged. Rather than tipping the continuum to one side or the other, chance and indeterminate performances strike a balance between signification and phenomenon.

This convergence of perspectives is also to be found in how distinct performance activities are perceived. Built into the context of traditional performances are certain framing devices that enable the spectator to distinguish "the performance" from other signifying elements, thus limiting the anxiety raised by Kirby's questions. The obvious gesture of entering a theatre or designated performance space is usually the first clue. All of the trappings of the "theatre" - costumes, lights, sets, props, text, acting style, space, etc. - help establish the sign "performance." If the piece is in the realistic or naturalistic mode, there is an implied understanding that the spectator is there to watch and appreciate but has no bearing on the action. To the left of the realistic dial would reside avant-garde performance, which actively works to disrupt this delineated model and might, for example, include the spectator within the performance structure. What these forms have in common, however, are signs that notify the audience of a specific type of performance.

Traditional performances frame the stage action as artificial, and signifying elements are to be seen as "fake-real," at least within the context of the narrative or performance. We don't necessarily believe that a character killed on stage means that the actor has also been killed, and we extend this willful suspension of disbelief to the remainder of the performance. What complicates this is that an indeterminate or chance-driven performance, when acknowledged as such, is often more "real" than its realistic counterpart. Chance and indeterminacy create, or at least play with, the idea of a "real-real," an actual unrepeatable phenomenon or experience that transpires in the present moment. It is this style of performance activity that leads to the development of the postsemiotic and the postdramatic. As Lehmann states, "In this postdramatic theatre of events it is a matter of the execution of acts that are real in the here and now and find their fulfillment in the very moment they happen, without necessarily leaving any traces of meaning or a cultural monument." ${ }^{20}$ This process, however, is more likely to occur when the spectator has acknowledged the intended performative frame. 
Clearly, one way to indicate the use of chance or indeterminacy is simply to announce it in either program notes or a prefatory statement. As this is often a clumsy way of getting the point across, there are often deliberate clues within the context of the performance that help the audience reach this understanding. Ironically, in order to get to the moment of phenomenological clarity in which the spectator is able to cultivate an awareness of a real event unfolding in real time, it is necessary to employ signs of "realness." One technique is a deliberate display of amateurishness, a method that signifies to the audience that the piece is constructed in avoidance of the slickness of traditional models. The deliberate use by postmodern choreographers and directors of untrained or non-professional performers, for example, helps establish this idea. As is often the case in certain performance art pieces, the inclusion of real blood, pain, terror, or fear will tip off the audience that this performance has both planned and unplanned elements. Chris Burden's early work and Yoko Ono's infamous "Cut Piece," in which she invited spectators to cut off pieces of her clothing while she remained passive, function in this manner.

Obvious display of indeterminate scores, options, or choices for performers also suggests the immediacy or "reality" of the performance. Situating the event in a non-performance space can magnify this process. In Lucinda Childs's 1964 piece Street Dance, for example, a section of a New York City street was designated as the performance space as informed spectators looked on from a window above. As Childs interacted with the environment, there was a collision of planned and unplanned elements, animating Kirby's question about the limits of theatrical signification. These "signs of realness" encourage the spectator to examine signification and phenomenon with no clear division between the two. Reminiscent of Cage's use of radios, here semiotics and phenomenology clearly intersect. The spectator must read the signs of indeterminacy and chance to arrive at the present moment only to use that moment to interpret subsequent signs.

While the work of people like Cage helped to generate a history of this activity, developing technology has the potential to expand the use of chance and indeterminacy exponentially. Multi-media performance has, like Cage's use of radios, extended this idea of indeterminate performance by using machines to "short-circuit human intention." Collaborating with Merce Cunningham in 1965, Cage created Variations $V$, in which the stage space was arrayed with photo-electric cells and antennae whose signals, when interrupted by the movement of performers, triggered changes in the light and sound. It is this type of activity that Brian Eno might refer to as "generative," or a technique in which the artist establishes parameters for a work, but employs a mechanical or computer-controlled process to arrange the pieces randomly. ${ }^{21}$ Eno, perhaps best known as the guru of ambient sound and the producer of $\mathrm{U} 2$ and the Talking Heads, has more recently returned to his roots as a visual artist. In 2006 he released his most ambitious project to date, 
77 Million Paintings, a work designed to utilize the infinite generative resources of digital media. Premiered as a traveling installation and subsequently commercially available as a computer software package (it has also been presented in the virtual online community Second Life), the program produces an estimated seventy-seven million images, a sequence of slowly changing light paintings capable of converting nearly any space into an installation environment (see fig. 1).

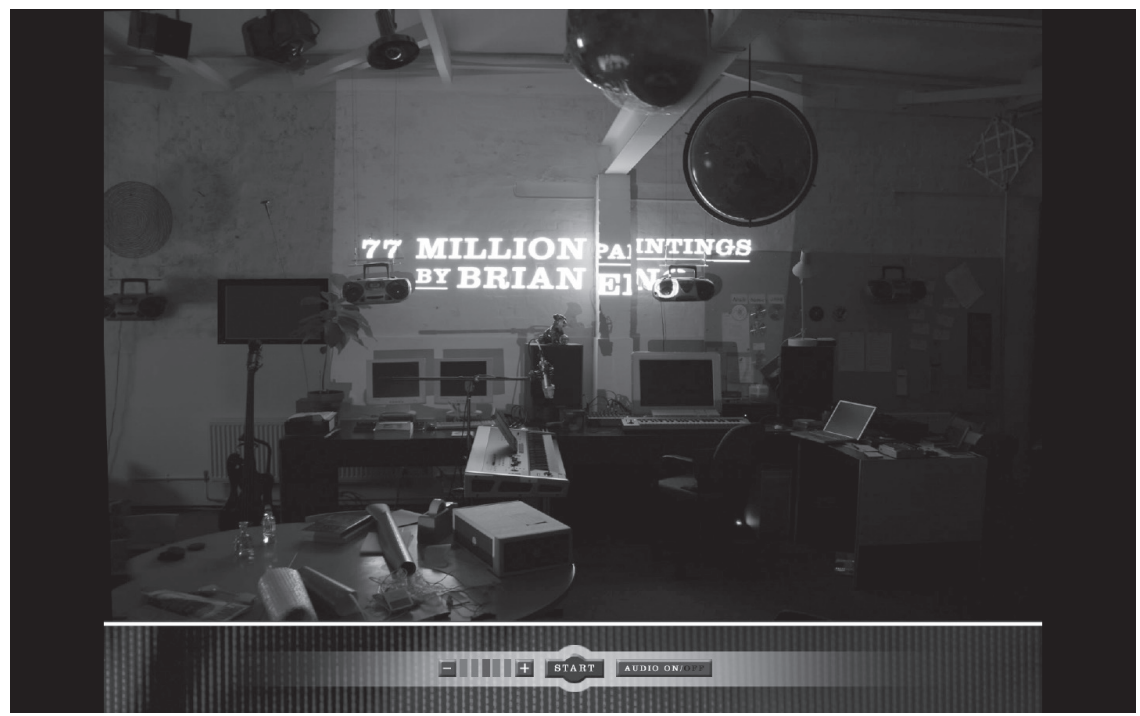

Fig. 1. 77 Million Paintings (2006), conceived and designed by Brian Eno and Lumen London Limited. (C) Brian Eno 2008.

Eno constructed this piece out of more than three hundred separate images, "most of them scratched or inked onto slides" which were then digitized. ${ }^{22}$ The images were derived mostly from paintings and photographs that, as Eno says, had "tactile or human interference." ${ }^{23}$ As one of his collaborators points out, "I was taking handcrafted elements and incorporating them into digital environments." ${ }^{24}$ Analogous to the combination of signifying elements and phenomenological moments in chance-driven performance, Eno's piece rests at the intersection of analogue and digital in which the generative qualities of the computer are blended with discrete handcrafted images. "In its final iteration, '77 Million Paintings' displays from one to four images on the screen simultaneously. Some of Eno's paintings are strictly background JPEGS; the rest are translucent PNG files that fade in and out above them." ${ }^{25}$ The end result is an ever-evolving sequence of unpredictable images produced by the combination of two or more known images, basically the visual equivalent of Raymond Queneau's 100000 Billion Poems. $^{26}$

The idea for this piece is rooted in Eno's exposure to two screensaver programs, Bliss and Stained Glass, in which he saw "the possibility of using the computer as a medium in which self-generating systems could be allowed to grow, rather than 
simply a way of moving big blocks of preformed data around." ${ }^{27}$ Despite the fact that Eno was instrumental in articulating the parameters for this program as well as generating the initial images, his role as "artist" quickly turned to that of "spectator" as even he was caught off guard by the resulting combinations: "I know all of the elements in the piece, of course, because I made them all, so you would think that I wouldn't be particularly surprised by any of the combinations of them, but I am very surprised, actually. The combinations are much more various and startling than I could have imagined." ${ }^{28}$ (see fig. 2.)

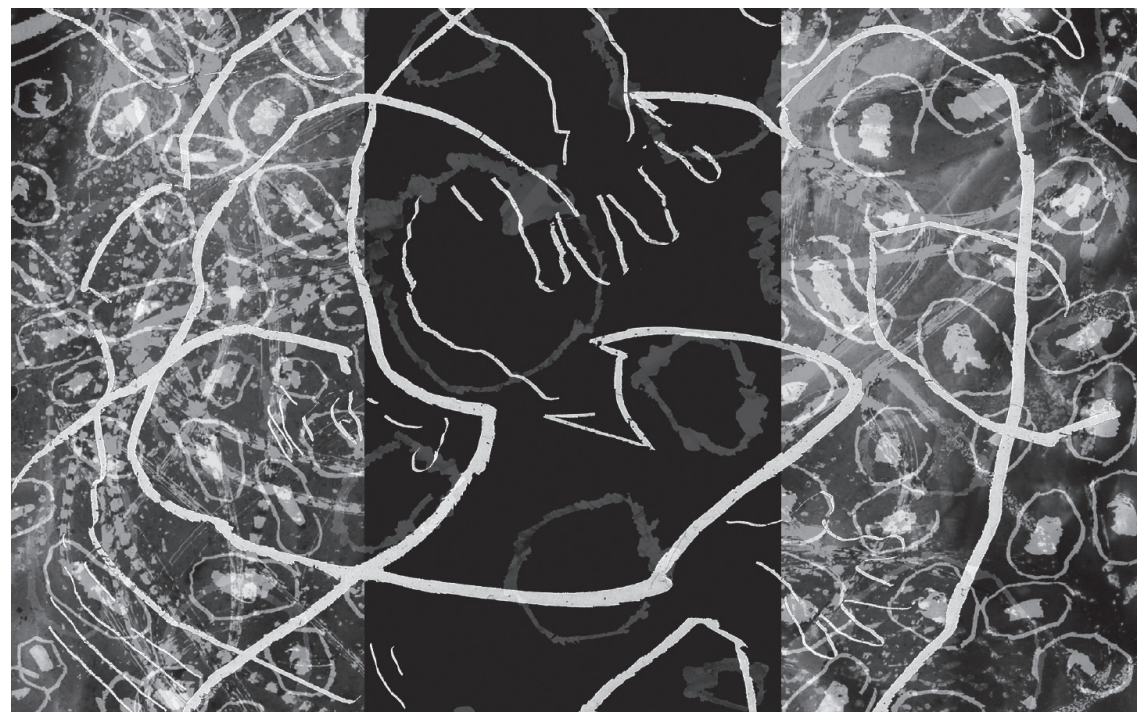

Fig. 2. 77 Million Paintings (2006), conceived and designed by Brian Eno and Lumen London Limited. (C) Brian Eno 2008.

Creating unique chance generated images, combined with music constructed by a similar process, Eno presents the viewer with an immediate experience that challenges the semiotic reading of recognizably encoded images. Although not technically a "live" performance, especially given that the viewer can choose when and where to have this experience, at what speed, and for how long, the piece unfolds in a linear, real-time format, and once viewed images dissolve to rarely, if ever, resurface again. ${ }^{29}$ As stated in the companion book to the DVD:

One way to approach this idea is to imagine that you have a large box full of painted components and you are allowed to blindly take out between one and four of these at any time and overlay them to make a complete painting. The selection of the elements and their duration in the painting is variable and arbitrarily determined. ${ }^{30}$ 
That is, the images are set; they are discrete and consciously composed semiotic objects. The context in which they are viewed, however, is indeterminate since the sequence of randomly generated digital environments alters the reception of each piece. It is with this aspect of his work that Eno is clearly building on the tradition of the avant-garde by creating a work of art that is not closed on meaning but open to innumerable interpretations.

The process of viewing this work reveals the fundamental issue at stake with indeterminate performance. Eno signifies the "real time" element of this piece in the title and prefatory comments, and within the context of the piece itself since it is nearly impossible for one viewer to see the same image twice. As I examine these generative images, I become aware of the fact that with seventy-seven million permutations it is quite likely that I am seeing an image that no one has ever seen before and no one will ever see again. ${ }^{31}$ While previous exposure to visual art enables me to comprehend these pictures - that is, they are not so unique that I can not compare them to the work of the Impressionists, Cubists, or Futurists - here is still a moment of phenomenological awareness in which I understand that these images exist only in the here and now (see fig. 3).

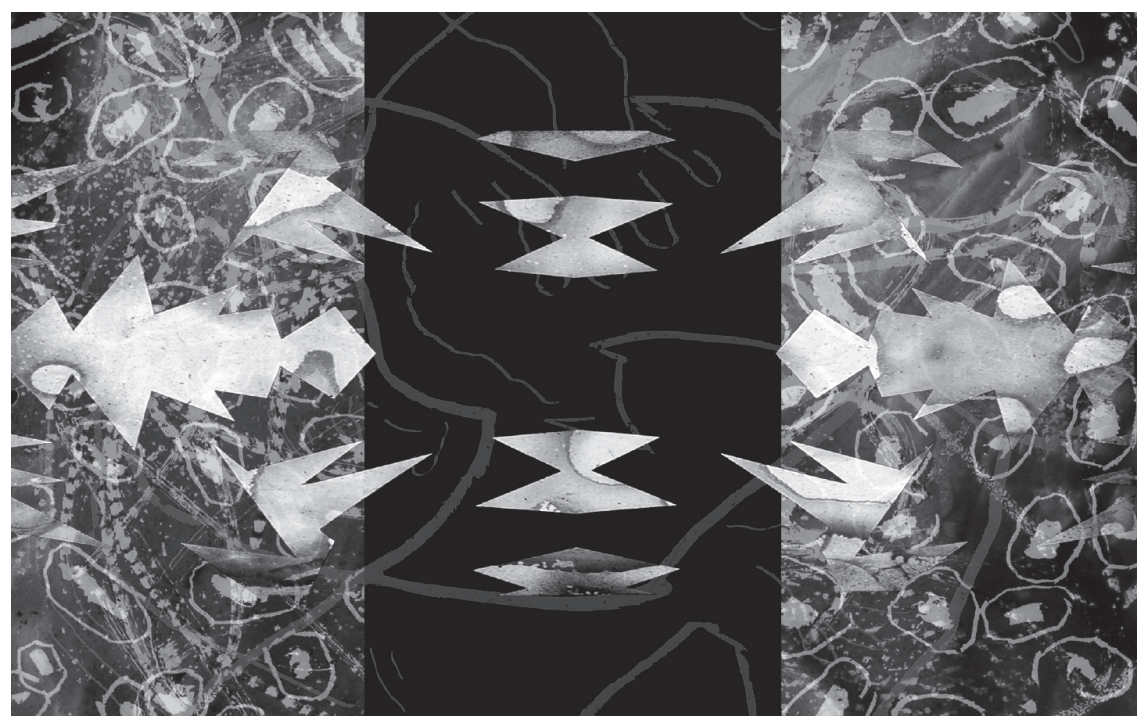

Fig.3. 77 Million Paintings (2006), conceived and designed by Brian Eno and Lumen London Limited. (C) Brian Eno 2008.

As I watch the piece unfold, however, immediate phenomenon gives way to signification as I become conscious of an emerging vocabulary of lines, shapes, patterns, and colors. The two approaches blur as the layered images slowly dissolve and evolve and the immediate phenomenon is reincorporated into the subsequent image, thus giving rise to signification. The present phenomenon becomes the future sign, which in turn become phenomenon and then sign and then phenomenon. 
Repeated or extended viewing reveals that, with a limited number of images, elements of previous combinations resurface as part of a new context. In this respect, the structure of this piece is reminiscent of the compartmentalization found in Cage's work and subsequent postdramatic theatre since it is a combination of discrete signifying elements within an immediate and randomly generated visual environment. Like any performative event built on indeterminacy in which the goal is not to construct a grand narrative, as a spectator I am free to pay attention or not. Like watching a Beckett play or a performance directed by Robert Wilson, I tune in and tune out; certain images and aural elements demand my attention, others simply register as white noise.

The key to this viewing process, however, is that each spectator navigates these elements differently, and the experience of the work changes from viewer to viewer. Yet, due to its generative structure, 77 Million Paintings transcends the ephemeral nature of live performance as the experience of viewing this piece changes not only from viewer to viewer, but also from viewing to viewing. Eno's work proposes a future of indeterminate art that utilizes available technology to generate unique inthe-moment experiences. As semiotics gives way to postsemiotics and the dramatic to the postdramatic, 77 Million Paintings, as a combination of analogue images and computer generated environments, can be considered a foundational piece in the emergent genre of postdigital ${ }^{32}$ art.

As an example of avant-garde art, Eno's work can be situated between the preand post-Cage artists Gertrude Stein and Allan Kaprow. Stein's notion of theatre as landscape, in which elements are perceived in relation to one another as opposed to through a narrative frame, is easily applicable to 77 Million Paintings. Unlike a work imbued with a specific meaning, the play as landscape, as Stein points out, "does not have to make acquaintance. You may have to make acquaintance with it, but it does not with you, it is there and so the play being written the relation between you at any time is so exactly that that it is of no importance unless you look at it." ${ }^{33}$ Like a landscape, the program runs according to its own internal logic, placing elements into relationships built on proximity, not signification. Since Eno constructed the work with a randomly generated set of parameters that create unique images that surprise even him, any sense of unity or "meaning" clearly rests with the viewer.

In addition to an affinity with Stein's notion of theatre as landscape, the piece is quite similar to Kaprow's "rules-of-thumb" for Happenings in which "the line between art and life should be kept as fluid, and perhaps indistinct, as possible." ${ }^{34}$ Often performed in public spaces with an indeterminate framework, Happenings are capable of incorporating all surrounding elements into the performance. The open structure of indeterminate art allows for unplanned or uncontained elements to be absorbed easily into and contribute to the overall experience. In this respect, "external" elements, which are often viewed as an interruption to traditional 
semiotically constrained performances, contribute to the phenomenological quality of indeterminate events.

This is also true of 77 Million Paintings. For instance, a colleague of mine has had Eno's piece running before, after, and in-between classes for the past year. Projected on the classroom's front wall, the piece has transformed an institutional space into an installation environment. While the work has defined boundaries, which becomes increasingly obvious with repeated viewings, its structure is flexible enough to admit a wide range of other elements into the mix. Student chatter, music, sounds external to the building, text read aloud, and other projections are not seen as an interruption; rather, they contribute to the generative uniqueness of each successive image. In fact, like Cage's 4'33', the open structure of this piece seems to court the inclusion of additional material.

Eno's piece, however, does have one crucial distinction that separates it from "live" performance. As a continually generated work of art that has at least seventyseven million starting points, it essentially has no beginning and no end. While it is possible to defer to Eno as the "beginning" of the piece, it has since evolved beyond even his imagination. Unlike live performance, which can disperse these elements but generally has a beginning and ending point, Eno's work is all middle. 77 Million Paintings is ultimately an example of what Deleuze and Guattari call the rhizome. An open rootless structure that spreads out in all directions at once, a rhizome "is composed not of units but dimensions, or rather directions in motion. It has neither beginning nor end, but always a middle (milieu) from which it grows and which it overspills." ${ }^{35}$ This aspect of Eno's construction places it beyond the notion of a contained and linear semiotic system into the realm of the postsemiotic. Assembled from fixed images but open to innumerable additional "outside" elements, presenting discrete images that are constantly in motion, and having multiple "starting" points, this work is clearly an example of the "both/and" of post-structuralism. Because of this, any reading of Eno's work must rely on cultural and personal experience (the semiotic) combined with immediate individual assessment (the phenomenological). Never settled, always in flux, and incorporating both chance and indeterminacy, 77 Million Paintings is clearly a work in the tradition of the avant-garde.

Post , in all of its permutations, exceeds the boundaries of a stable and well-ordered system. As each of these terms is a hybrid suggesting past and future, category and beyond category simultaneously, they are indicative of artworks and methods of analysis that are not funneled into a solitary meaning. Each term suggests a pathway from one idea to the next that would not be possible without the initial idea. But, as the notion of a pathway indicates, there are elements that lie outside the boundaries of its edge. Performance critics like States, Kirby, and Lehmann articulate the boundary points with regard to semiotics and drama. Groups like the Dadaists alongside artists like Cage and Eno provide examples and processes that challenge these boundaries by creating experiential works that 
collapse the distinction between semiotics and phenomenology. The avant-garde techniques of chance and indeterminacy facilitate the creation of works that exist in real space and real time and beg the question: "How do you read a sign that no one has ever seen before?" This will always be a negotiation between the sign and the phenomenon, between what you know and what you experience.

\section{Notes}

1. Keir Elam, The Semiotics of Theatre and Drama (London: Routledge, 2002) 200.

2. Hans-Thies Lehmann, Postdramatic Theatre (London: Routledge, 2006) 27.

3. Roland Barthes, Image, Music, Text (New York: Farrar, Straus, and Giroux, 1977) 61.

4. 32 (italics in original).

5. Michael Kirby, a formalist theatre (Philadelphia: U of Pennsylvania P, 1987) 34.

6. 37 .

7. Bert O. States, Great Reckonings in Little Rooms (Berkeley: U of California P, 1985) 6-7.

8. Since the intent of this paper is to explore the shift from semiotics to post-semiotics I have chosen to include critics who question the usefulness of semiotics as opposed to those who support it.

9. In his study of "phenomenology and performance in contemporary drama," Bodied Spaces (Ithaca: Cornell U P, 1994) Stanton B. Garner, Jr. defines the central aim of phenomenology as pursuing "the thing as it is given to consciousness in direct experience; to return perception to the fullness of its encounter with its environment" (2).

10. Bert O. States, "The Phenomenological Attitude," in Critical Theory and Performance, eds. Janelle Reinelt and Joseph Roach (Ann Arbor: U of Michigan P, 1992) 370.

11. States, Great Reckonings 8.

12. Kirby, a formalist theatre. Brian Eno refers to this type of idea as "axis thinking," a term for "a continuum of possibilities between two extreme positions." Brian Eno, A Year with Swollen Appendices (London: Faber and Faber, 1996) 298.

13. Christopher Innes, Avant-Garde Theatre (London: Routledge, 1993) 19.

14. Robert Motherwell, The Dada Painters and Poets, $2^{\text {nd }}$ ed. (Cambridge, MA: The Belknap P, 1981) 76.

15. 92.

16. Richard Kostelanetz, Conversing with Cage (New York: Limelight Editions, 1988) 17.

17. Michael Kirby, "The New Theatre," The Tulane Drama Review 10.2 (Winter 1965): 33, 34.

18. Michael Kirby and Richard Schechner, "An Interview with John Cage," The Tulane Drama Review 10.2 (Winter 1965): 57.

19. Richard Kostelanetz, The Theatre of Mixed-Means (New York: RK Editions, 1980) 56.

20. Lehmann, Postdramatic Theatre 104.

21. Eno cites Steve Reich's work with increasingly out of synch tape loops on such early pieces as "It's Gonna Rain" as the inspiration for this process. One of the first generative pieces Eno created was Discreet Music (1975). As he points out, "I have gravitated toward situations and systems that, once set into operation, could create music with little or no intervention on my part" (Liner notes for Discreet Music: Virgin Records, 2004). Claiming to have inhabited the roles of planner and programmer and then audience listening to the results, Eno set up a long delay echo system and then chose what sound to input. Basically, this work consists of two or more simple melodic cycles of different lengths separately repeating and overlaying each other arbitrarily. He points out, "it is a point of discipline to accept this passive role, and, for once, to ignore the tendency to play the artist by dabbling and interfering" (Liner notes for Discreet Music).

22. Dustin Driver, "Brian Eno: Let There be Light" Apple Computer, 12 February 2007. <http:// www.apple.com/pro/profiles/eno>

23. Brian Eno, 77 Million Paintings (All Saints Records, 2006). Includes painting software DVD, interview DVD, and companion book with an essay by Eno.

24. Driver, "Brian Eno: Let There be Light."

25. Driver, "Brian Eno: Let There be Light."

26. Published in 1961, Queneau's Cent mille milliards de poèmes consists of ten sonnets whose lines are interchangeable due to the fact that the book was designed for each line of each poem to be cut into a separate strip of paper. The result is a seemingly inexhaustible number of combinations.

27. Eno, A Year with Swollen Appendices 307. 
28. Sylvie Simmons, "Brian Eno's '77 Million Paintings' is an artwork that won't sit still," The San Francisco Chronicle 27 June 2007: E1.

29. Eno has estimated that it would take a continuous viewing of over 450 years to see all of the possible images.

30. Eno, 77 Million Paintings.

31. The increasing library of published images, this article included, clearly tampers with Eno's "real time" intentions for the piece.

32. Postdigital is a term gradually coming into vogue to describe artistic processes that do not focus on the digital tools themselves, but ask what artistic possibilities these tools afford. It is not an abandonment of digital for analogue ideals, but like the postsemiotic, a movement from one phase to another. For an excellent discussion of this idea, see Kim Cascone, "The Aesthetics of Failure: 'Post-Digital, Tendencies in Contemporary Computer Music," Computer Music Journal 24.4 (2000): $12-18$.

33. Gertrude Stein, Writings and Lectures 1909-1945 (Maryland: Penguin Books, 1971) 77.

34. Allan Kaprow, Assemblages, Environments \& Happenings (New York: Harry H. Abrams, 1966) $188-9$.

35. Gilles Deleuze and Félix Guattari, A Thousand Plateaus (Minneapolis: U of Minnesota P, 1987) 21. 
